\title{
Coulisses
}

Revue de théâtre

15 | Hiver 1997

Varia

\section{Le théâtre de signes}

\section{Pierre Louis}

\section{OpenEdition}

Journals

Édition électronique

URL : http://journals.openedition.org/coulisses/5066

DOI : 10.4000/coulisses.5066

ISSN : 2546-9460

\section{Éditeur}

Presses universitaires de Franche-Comté

\section{Édition imprimée}

Date de publication : 1 janvier 1997

Pagination : 41-43

ISSN : 1150-594X

\section{Référence électronique}

Pierre Louis, «Le théâtre de signes », Coulisses [En ligne], 15 | Hiver 1997, mis en ligne le 26 avril 2019, consulté le 23 octobre 2019. URL : http://journals.openedition.org/coulisses/5066 ; DOI : 10.4000/ coulisses.5066

Ce document a été généré automatiquement le 23 octobre 2019

Coulisses 


\title{
Le théâtre de signes
}

\author{
Pierre Louis
}

1 L'Annonce faite à Marie est un reflet de la longue carrière de dramaturge, de poète et d'essayiste qu'a parcourue Claudel: cinquante-six ans de patience acharnée, quatre naissances ou renaissances, en comptant le drame initial, La Jeune Fille Violaine.

2 La première version fut présentée au public du théâtre de l'œuuve à Paris en 1912: public restreint, dans un théâtre d'avant-garde, mais succès. Seconde version en 1938 jouée en 1941 et en 1946. Version définitive pour la scène en 1948: "c'est le couronnement de mon œuvre dramatique et poétique » déclare Claudel.

3 L'attachement de l'auteur à cette pièce provient de ce qu'il a cherché à retrouver, dans l'histoire de Violaine, sa propre enfance : «il a fallu les longues et amères rêveries d'un enfant dans un village nourri d'histoire, adossé au mystère et ouvert à la contemplation... »Et Claudel a voulu également exprimer sa foi, pleinement, sans retenue, jusqu'à mêler théâtre et liturgie. En renouvelant son inspiration et son style : l'élément subjectif est présent mais ne domine plus. La composition prend le pas sur l'inspiration. Les thèmes développés à partir d'une intrigue relativement simple (l'histoire de la rivalité de deux sœurs,) ne le sont pas pour eux-mêmes, mais parce qu'ils produisent des signes qui, reliés entre eux, manifestent les réalités invisibles enjeu dans le drame et enjeu du drame.

4 Par exemple, le thème du départ - le départ involontaire de Pierre de Craon, le départ inopiné d'Anne Vercors qui laisse sa famille en désarroi, le départ obligé de Violaine vécu par Jacques comme un abandon et par Mara comme un remède pire que le mal. Le départ est le moyen de la progression dramatique. Sans lui, rien de théatral ne se passerait et les personnages ne "goûteraient » pas à la liberté. La maîtrise de Claudel est d'avoir donné à ces trois départs une valeur d'action pour le drame visible et pour le drame invisible: quelque chose se passe qu'on ne voit pas, qui prend le contrepied de ce qui arrive et qui finit par arriver quand on croit qu'il ne va rien se passer. C'est ce que Claudel appelait «le sacrement de l'absence » qui révèle bien sûr l'existence d'un autre personnage, cet Autre qui a exigé la séparation pour que s'opèrent une libération, une fécondité plus grande que celle d'une union charnelle banale. 
5 Autre thème, autre élément signifiant d'un point de vue dramatique : la lèpre, signe de punition divine dans l'imaginaire collectif, transmué en signe de la vocation de Violaine, symbole visible de l'œuvre de la grâce, par combustion si l'on peut dire, à partir du moment fatal du baiser donné au lépreux qui déclenche, là encore, un désastre apparent et, en même temps, le feu de l'Amour.

Enfin, Claudel a voulu que son drame s'inscrive sur un plan plus vaste que celui de l'histoire d'une famille de riches paysans à la ferme de Combernon. Il a voulu relier cette histoire à l'histoire d'un peuple, d'une nation en train de se constituer, et à l'histoire de l'Eglise. D'où la transposition à la fin du Moyen Âge et l'utilisation du miracle, comme élément organique de toute la pièce, comme prodige mais surtout comme signe, la goutte de lait posée sur la bouche de l'enfant revenue à la vie délivrant le sens de la pièce.

7 De ce fait, le ton de la pièce était trouvé, ce serait celui d'un mystère moderne, c'est à dire d'une représentation des passions humaines rattachées au plan catholique inspirée ici ou là de légendes et de pages de l'Ecriture sainte. Le propos était affirmé : raconter en quatre actes et un prologue, l'histoire de la lutte de l'homme contre l'appel de Dieu, dans le langage qui convient, c'est-à-dire à la fois familier et sublime.

8 La mise en scène d'une telle pièce pour une tournée qui devait nous conduire dans des lieux de nature différente (églises, théâtres, auditorium), loin de son lieu de création (l'avant-cour de la place d'armes du château de Joux) allait s'inscrire dans un espace clos tendu de velours noirs.

9 Sobriété, dépouillement, symbolisme des éléments de décor et des effets lumineux allaient caractériser notre parti-pris. Nous nous sommes attachés à restituer l'humanité concrète des personnages aux prises avec le sacré, chacun à sa manière non dénuée de fantaisie et de verve.

D'où un lyrisme contenu, un jeu entraînant, l'intrusion de quelques éléments burlesques, une musique de fanfare villageoise, des réminiscences de la vie paysanne de la fin du XIX $\mathrm{X}^{\mathrm{e}}$ siècle. Donner à voir combien Claudel avait la tête pleine de prophètes mais aussi la bouche pleine de gourmandise...

\section{ANNEXES}

L'Annonce faite à Marie

Paul Claudel

Comédiens des Nuits de Joux / C.A.H.D. scène départementale 25

Création au Château de Joux dans le cadre du Festival des Nuits de Joux en Août 1995

Tournée automne 96

avec l'aide du Conseil Général du Doubs et de la Ville de Pontarlier

Vendredi 25, Samedi 26, Dimanche 27 octobre 
Eglise de La Rivière-Drugeon

Saison 96-97 : 290 spectateurs

Mercredi 6 novembre

Théâtre du Casino YVERDON (CH)

saison $96-97: 150$ spectateurs

\section{Samedi 9 novembre}

Théâtre Beau Site

LA CHAUX DE FONDS (CH)

Théâtre Populaire Romand

saison $96-97: 100$ spectacteurs

Jeudi 14, Vendredi 15 novembre

Cathédrale Saint Jean

BESANCON : 340 spectateurs

\section{Mardi 19 novembre}

Théâtre d'EPINAL, Les Amis du Théâtre Populaire

saison $96-97: 380$ spectateurs

\section{Samedi 30 novembre, Dimanche $1^{\text {er }}$ décembre}

Crypte de la basilique de Fourvières LYON

(manifestation officielles du Centenaire de la basilique de Fourvières) : 450 spectateurs

Mercredi 4 décembre

Théâtre de Sion (Valais) $(\mathrm{CH})$

saison $96-97: 370$ spectateurs

Total : 2080 spectateurs

DISTRIBUTION

Lorraine PRIGENT : Violaine Vercors

Christian PAGEAULT : Anne Vercors

Claudine BERTHET : Elisabeth Vercors

Béatrice BOMPAS : Mara Vercors

Miguel FERNANDEZ : Jacques Hury

Mathieu LOISEAU : Pierre de Craon

Mise en scène de Pierre LOUIS 